Hargreaves, E; (2013) Inquiring into children's experiences of teacher feedback: reconceptualising

Assessment for Learning. Oxford Review of Education , 39 (2) pp. 229-246.

10.1080/03054985.2013.787922. Downloaded from UCL Discovery:

http://discovery.ucl.ac.uk/1471462

\title{
ARTICLE
}

\section{Inquiring into children's experiences of teacher feedback: reconceptualising Assessment for Learning}

\author{
Eleanore Hargreaves \\ Institute of Education
}

\begin{abstract}
Few previous studies have explored in detail how children respond affectively and cognitively to feedback in the normal interactions of the primary school classroom and how they relate the feedback to their sense of autonomy. This paper reports on a longitudinal study of nine 'profile' children aged 9 to 10 years in a UK school. They were observed and video-filmed in threes, twos or individually during literacy and numeracy lessons across two terms from January to July 2010. The video-recordings were shown to the children who had been filmed later the same day, being stopped at frequent intervals to allow the participants to comment on specific feedback incidents. The children claimed that learning was frustrated by overly directive feedback, that their learning benefited when the teacher's feedback included substantial but not burdensome detail. The children felt their learning was supported by feedback reminder cues and they noticed that negative and positive feedback provoked emotions which could interfere with or support learning. The article concludes by suggesting that Assessment for Learning might be conceptualised as a classroom conversation in which children as well as teachers assess how teacher feedback relates to children's learning, which would itself constitute a major contribution to their autonomous learning.
\end{abstract}

Keywords: Assessment for Learning; feedback; autonomy; teaching and learning.

\section{Introduction}

Specific mechanisms that relate feedback to learning are still mostly murky, with very few (if any) general conclusions (Shute 2008, 156).

Despite six recent mega-reviews about feedback (Hattie and Timperley 2007; Kluger and DeNisi 1996; Mason and Bruning 2001; Mory 2004; Narciss and Huth 2004; Shute 2008), we still lack many details about how feedback helps children's classroom learning. This lack may be partly a consequence of the fact that the child's perspective on feedback is frequently missing from research into feedback (although see Torrance and Pryor 1998 and Tunstall and Gipps 1996a, 1996b for studies in infant schools; Weeden, Winter and Broadfoot 2002, and Brookhart 2001 in secondary schools). Without the learner's perspective, the crucially important affective and interactional aspects of learners' responses to feedback are likely to be missing. Butler and Winne (1995) point to the complex and individualised nature of knowledge construction and suggest that any feedback message given by a teacher may be appropriated differently by each individual learner and so affect the learning process in a particular way. They point out that existing feedback studies tend to 
focus on the feedback given by the teacher and the child's achievement, rather than on how the individual child responds to the teacher's feedback within the feedback interaction. Indeed, many earlier studies of feedback were conducted in experimental conditions, rather than natural settings such as classrooms, and several major studies related to computergenerated feedback (e.g. Azevedo and Bernard 1995; Narciss and Huth 2004) or noneducational settings (e.g. Kluger and DeNisi 1996), none of which take account of the affective and interactional dimensions in understanding classroom feedback. In this paper, by contrast, I describe the reactions of the children themselves, as they recount these reactions during a video-replay of their classroom lessons. These accounts highlight differences as well as similarities across the nine children and across different situations.

Despite the prominent position given to feedback within the international discourse of Assessment for Learning (AfL), research into feedback within the context of AfL is particularly lacking. That is, there has been scant research into feedback whose aim is not just to report results but explicitly to support children's autonomous learning (Marshall and Drummond 2006). Emphasis on students as autonomous directors of their own learning is now considered to be central to successful learning and its sustainability (Dennison and Kirk 1990; and Murnane and Levy 1996). Autonomous learning is defined variously as learning in which children take the initiative, learning in which children act independently, learning in which children assume a critical stance or, most fully, as the combination of these (Ecclestone 2002). Independent learning seems to be easier to achieve than autonomy in its broadest sense (DCSF 2008), but independence achieved without the child using initiative or assuming a critical stance to the situation can serve limited instrumental ends. In accord with Ecclestone (2002), Pryor and Crossouard (2008) and Torrance and Pryor (1998) among others, I suggest that it is children's learning autonomy in its fullest sense that is ultimately valuable in AfL, and it therefore becomes important to find out from the children themselves how their interpretation and use of teachers' feedback relates to their sense of autonomy. Earlier studies that have been conducted in classroom settings have tended to focus on convergent assessment situations where children are looking for correct answers for a single test or performance rather than classroom learning situations where autonomous learning is encouraged. Specifically, the teacher's role in supporting autonomy through feedback is under-researched. This paper therefore explores how some Year 5 learners (aged 9 to 10 years) in a UK classroom experienced their teacher's feedback, in particular as it supported or hindered their autonomous learning defined as children taking the initiative, acting independently and assuming a critical stance.

Torrance and Pryor (1998) have identified a range of assessment approaches with 'convergent assessment' at one end of the spectrum and 'divergent assessment' at the other, the former being most common in primary classrooms (see also Name; Name; Pryor and Crossouard 2008). Feedback within a convergent framework focuses on the elicitation of correct answers and identifies errors in a child's performance (see also Black and Wiliam's 'directive' feedback 1998; and Hattie and Timperley's 'task-focused feedback' 2007), while within a divergent framework, feedback is 'exploratory, provisional or provocative' (Pryor and Crossouard 2007, 4), often encouraging children to reconstruct their thinking about the subject domain or learning process (see also Black and Wiliam's (1998) 'facilitative' feedback; and Hattie and Timperley's (2007) 'process-focused/self-regulationfocused' feedback). If feedback springs from the teacher's desire to provoke the learner to generate his/her own negotiated ideas, including critical ideas, then provocative feedback within a divergent assessment framework could contribute to the development of learning autonomy, including some critical autonomy, in the classroom. On the other hand, feedback useful for meeting specific targets and for controlling behaviour gravitates towards the 'convergent' extremity, and so potentially clashes with the autonomy aim in its fullest sense. Whilst these frameworks are useful conceptual tools, in the research described below I tried to find out how the learners themselves experienced them practically and thus also aim to break with the tendency to categorise feedback as inherently 'good' or 'poor'. 


\section{Research design}

The research described in this article began in October 2009 and was completed in July 2010. Final interviews in July 2010 focused on how the children had experienced the research process. The aim of the research was to understand the children's perspectives on their teacher's feedback in relation to their learning. My epistemological stance was informed by the principles of constructivism, defined as understanding the multiplicity of social constructs, meaning and knowledge (Robson 2007, 27). I was particularly interested in the differences among the children's perspectives as well as similarities. While the research was carried out only in one classroom, a range of nine children there described in great depth a variety of responses to feedback across a mix of settings. Therefore, although no generalisations can be made in relation to the data, the study can provoke in the minds of researchers, teachers and policy makers with an interest in AfL, further scrutiny of existing traditions of feedback. At the very least it might provide what Bassey $(2001,5)$ calls 'a powerful and user-friendly summary which can serve as a guide to professional action'.

The principal method for this research was group, paired or individual interview based on video-tapes of classroom observations. Initially I interviewed, in groups of five or six, twentyseven children in a Year 5 class taught by 'Mrs. K' at a state-funded primary school in Surrey, UK. The parents of the children were sent a letter outlining the aims and planned processes of the project, and asking parents to opt out if they were not comfortable about their child taking part. On the basis of the initial group interviews (reported elsewhere in Name), in December 2009 I selected nine 'profile' children. Five girls and four boys were selected in consultation with the class teacher, because in the initial interviews, these children seemed enthusiastic and had a range of insights into teacher feedback. They spanned the ability range in terms of National Curriculum attainment levels, with three attaining lower levels, four attaining higher levels and two who were considered average.

From January until July, I observed and video-recorded one, two or three of the nine children nearly every week of two terms, during either a literacy or a numeracy lesson. Later the same day, I then showed the selected children the video-recording of that lesson and interviewed them to find out their responses to the teacher's feedback in the lesson. I played the video to them, pausing at each feedback episode and asking the children to tell me about what was going on. Sometimes I used questions such as, 'What did the teacher mean then?', 'Why is she saying that?' and 'What did you think [or feel] about that?' Each individual interview lasted about one hour and most were held in the privacy of the music studio, which was a freestanding and sound-proofed room next to the children's classroom. The key advantages of using interviews following observation was that they helped reveal the meanings children attributed to the teacher's feedback, and their understandings of this phenomenon. Video-footage of the feedback they had experienced helped them to remember the feedback episode and to describe the meanings and understandings they attached to it. Because of the authentic nature of the video-taped situation and because of the longitudinal aspect of the research design, this method led to complex data which yielded insights not only into children's responses to a range of feedback over several months but also the contexts within which the feedback was used. A total of 17 hours of interview data was collected in this way, in addition to individual interviews conducted with each child about their experiences at school generally.

Data were analysed through progressive focusing and identifying new themes (Miles and Huberman 1995). I started by looking for themes already highlighted in the feedback literature (cited above). All themes were then categorised into related clusters, which included those labelled initially as follows: autonomy; ineffectual feedback; inhibiting emotions; encouraging emotions; praise; and children's experiences of participating in the research project. New themes were then identified which were sometimes off-shoots of earlier themes. For example, initially the theme of ineffectual feedback as the teachere simply 'telling' was pursued, but then different versions of the theme of 'telling' emerged. 
These included: the children's perception that the teacher kept repeating her feedback; the contrasting suggestion that at some points the children did simply want to be told; and the supplementary claim that they needed more detailed feedback from the teacher, especially feedback in which strategies for solving problems were suggested. As the analysis progressed, it became clear that there was a tendency for the lower achieving children to resist more explicitly the teacher repeating her feedback and simply telling them what to do, while higher achievers tended to ask for more detailed and more frequent feedback. This school in Surrey, UK, was selected because it was considered in the area to be an excellent school with a head teacher who himself was open to academic research and willing to learn through it. It had a history of good OFSTED reports and a reputation as a thriving community. The head teacher suggested that I work in Year 5 with Mrs K. because Mrs K. was a confident teacher whose classes achieved well and who was good at taking advice on board. She had been teaching at the school since she was a Newly Qualified Teacher, seven years previously. Mrs K. herself was willing to take part in the research, although anxious about being video-recorded. Once the research began, she seemed more comfortable and confident and was very willing to make arrangements to suit the research work. Mrs K. advised me of good sessions to observe and appropriate times for interviewing the children. She usually spent some time sitting with the group containing the children I was observing so that I was sure to record some individual feedback interactions with them.

Ethical issues need to be addressed carefully when working with young children as research participants. A few parents were worried that the children were being 'used' for purposes of which they were unclear and expressed concern over disruptions that the video camera might cause. A special letter was therefore sent out, explaining the purposes of the project more fully than the initial information letter, and reassuring parents that interviewing children about what helped or hindered their learning was often beneficial to their learning (Watkins 2001). A guarantee was given that I would cease video-recording if it became a source of disruption, but this did not happen.

\section{The children's participation in the research}

The following video-based interviews were held with the nine profile children between January and July 2010. All nine children had previously been interviewed twice during nonvideo-based interviews, in the whole class small groups and then individually about their general experiences of school (reported in Name). Subsequently, as shown on the table below, most children were interviewed a further two, three or four times in video-based interviews. This article draws on these video-based interviews.

\section{TABLE 1. CHILDREN'S VIDEO-BASED INTERVIEWS}

When I first met with all the children in small groups, I explained that I worked for a university and that some university researchers were interested to know what children thought about their own learning and how the teacher supported this by her comments. They were told that researchers wanted to make the learning experience better for children. The profile children were assured that their comments would be anonymised if they were fed back to any teacher in their school, and for this reason pseudonyms have been given to the children in this paper. During the two terms of interviewing, the children sometimes expressed doubt about this confidentiality and were keen to be reassured that their teacher would not know what they had said. For example, near the end of the first term Aaron was heard warning his partner that the words he said might be held against him. This fear was partly fear that their teacher would become angry with them about their comments, which seems counter-intuitive given the teacher's mild manner and the fact that Mia rated the chance of her growing angry at one per cent. Farhana, Maddie, Laila and Aaron noted that they were just reluctant to upset their teacher, of whom they were fond. Laila explained: 'I don't really want to offend people. I wouldn't feel very good about myself'. The children gave their informed consent to be observed and interviewed on each separate interview and observation occasion and they 
were always free to withdraw. However, no child declined being observed or interviewed, although on a couple of occasions a child chose to leave the interview a few minutes early.

The profile children commented on the use of microphones and video-cameras in class and during interviews. Esther commented, 'It's scary, because it's unusual, but it's quite fun'. Wayne, who tended to have poor concentration in class, was the most distracted by the video camera and can be heard on tape several times to comment on his own image in the camera as the class progressed. Wayne, Dave and Laila, the three lowest achievers, were most conscious of how they looked and sounded when recorded, but they still volunteered valuable insights into their learning processes.

Overall, the children said that they benefited from being part of the project, for three reasons. Firstly, three of the boys liked missing their lessons to take part in interviews. Aaron explained: 'It's nice to be able to just come here and actually do something different'. Wayne was relieved to be in a context where he could express himself verbally rather than through writing, which he found hard. On the other hand, four of the children regretted having missed 'the fun subjects' such as art and ICT, and Laila believed she could not afford to miss numeracy lessons. Most of the children seemed to have the perception that they had missed some numeracy and literacy lessons for interviews, even though this was purposely never the case since all interviews had been held in the afternoon when other subjects were being taught.

Secondly, the profile children liked participating in the research because they had a sense that their involvement might change classroom life for the better. Dave, Esther, Maddie and Mia were particularly aware of this. As Maddie expressed it, 'If you want to make a change, then you probably can'.

Thirdly, and most significantly in relation to the theme of learning autonomy, all the profile children appreciated being asked their views. I noticed that some children were better able to express these than others: Wayne, Aaron, Maddie, Esther and Mia could be quite frank from the beginning, while it took, Farhana, Laila, Dave and Josh longer to express themselves openly. Laila and Farhana recounted how they grew more confident in being open as the months passed. Laila summed this up: 'I learnt to, like, to tell the truth and not to keep it bottled up'. Esther admitted that she used to 'twist the truth' a bit to start with, until she realised that I really wanted to know what she thought. Mia and Farhana said the interviews were boring to start with, until they realised that they could be completely honest, something that they did not always expect in school (see Fisher 2011 for an exploration of children's habit of hiding their true feelings at school). Josh noted that as the months wore on, they became better able to give detailed answers to my questions because they had got to know their teacher better, and had also had more feedback experiences to consider. Josh and Esther both agreed that they were now better at getting their points across generally.

\section{Children's comments about the teacher's feedback}

The following section summarises how the profile children described their experiences of the teacher's feedback. The section focuses on the following four findings:

- The children claimed that learning was frustrated by overly directive feedback

- They said their learning benefited when the teacher's feedback included substantial but not burdensome detail

- The children felt their learning was supported by feedback reminder cues

- They noticed that negative and positive feedback provoked emotions which could interfere with or support learning.

The children claimed that learning was frustrated by overly directive feedback The following exchange occurred between Dave and his teacher during a lesson in which the children wrote down their reflections on the experience of making wooden catapults: 
[Teacher to Dave:] Right, not just one word, we need it in a sentence, Dave. Exactly what we were just talking about. I said to you about- do you know what you're going to write about in the sentence, then, Dave?

Dave: Concentrating on Wayne yelling in my ear.

Teacher: Er, in a full sentence. "Concentration would be hard with people distracting me." Rather than "yelling," we'll have maybe the word "distracting."

Dave told me he felt like a postman because the feedback he received concerned delivering, rather than authoring, writing. The interview ran as follows:

EH: Okay. So do you wish [the teacher] hadn't given you an example?

Dave: ...

Dave: If I ask for help, I need help, but most of the time I come up with stuff on my own.

EH: Yes. So how does that make you feel when she does it for you?

Dave: I'm not sure. Probably... I'm not sure what it's called, but someone has the idea, and you just write it down for them, it's weird.

EH: You end up feeling like a...

(Long pause.)

Dave: Postman.

EH: Postman?

Dave: Yeah, because they have to deliver letters.

His point suggested that the teacher should not feed back to the child when the child could direct him or herself. With pressure on teachers to 'deliver' an externally prescribed curriculum in limited time, it is striking that Dave here uses the word 'deliver' in the context of his own delivery of the teaching material. A considerable amount of frustration was felt by seven of the nine the children [Dave, Laila, Farhana, Maddie, Mia, Josh, Esther] when their teacher continued to give feedback after it was necessary. Strikingly, this seemed particularly the case for four children, Dave, Farhana, Laila and Maddie, who were the lower achievers. Perhaps they were sensitive to being told they were wrong and corrected. This finding is not reflected in other literature; indeed, some teachers are exhorted to 'scaffold' lower achievers with direct help (Yandell, 2007).

Maddie commented that if the child knew how to use a question mark, then the teacher should move on instead of '... having to go RAH RAH RAH about question marks and stuff'. It is notable that Maddie used the words 'having to' in relation to the teacher's feedback role, as though she detected some external controlling force. During one observation, I saw Wayne vividly acting out to his group a demonstration of the word 'glimpse' only to have the word subsequently explained by the teacher. Laila told me that when the teacher kept repeating her feedback:

It made me not listen and it was really annoying. I can do this, but you keep repeating it, actually distracting me instead of- because I was told to think, and then-

In keeping with Hattie and Timperley's (2007) finding that cues and prompts rather than direct answers lead to longer lasting effects, Farhana told me that she found it more helpful to have to look up a spelling rather than having it spelt out for her. She commented, 'You would remember how to spell it because you did it'. Likewise, Esther preferred the teacher to give her feedback using a question, because this provoked her to think more deeply for herself. Mia and Josh were seen spontaneously to use other children's responses as a trigger for checking their own. 
Of great significance was the finding that Laila attributed being overly directed to the fact that she was on the 'lower table' and thus seen as a struggling learner: her sense was that the teacher told the higher achievers how to do something, but simply gave lower achievers the answer instead. She clearly believed that the teacher did not feel it worthwhile to explain details to her. However, three children, Farhana, Maddie and Mia who were higher achievers, complained that sometimes the teacher also told them the answer without explaining how to reach it. In summary, the majority of the children, including all the lowest achievers, said they would have preferred more opportunities to draw on their own agency before being given an answer by the teacher as feedback. This echoes Shute's $(2008,167)$ summary finding, drawing on existing feedback reviews, as follows:

Delayed feedback may encourage learners' engagement in active cognitive and metacognitive processing, thus engendering a sense of autonomy (and perhaps improved self-efficacy).

However, such an explicit echoing of Shute's research finding, in terms of children's resentment towards the teacher for 'spoon feeding,' is perhaps a novel emphasis in some primary classrooms.

On the other hand, Mia said,

Sometimes it's a bit annoying when you need more help, but then she doesn't -, she just says, 'Work it out', and you're thinking, 'Well, how?' But if you don't get it, how can you try? Because you don't know how to do it.

It seems, then, that even though the children were sometimes frustrated when the teacher fed back too much too early or for too long, at other times they clearly wanted more obvious cues and prompts, or even answers. Josh agreed that he needed the teacher's feedback in order to do his best because she normally had better ideas than he had. Laila was particularly frustrated at being told what to do during one DT session, but on another occasion she said it really helped her to hear the teacher's same feedback three times. Maddie tended to want directive feedback as she explained that it stopped her from just 'lazing back'.

The children said their learning benefited when the teacher's feedback included substantial but not burdensome detail

Farhana said, 'She tells you quite a lot of stuff to improve on. I say, "That's fine". You take it all in, but you can forget it when you're writing'. This comment chimes with the feedback research which stresses the necessity for manageable units of feedback (Shute, 2008). More generally, feedback cannot help children to take any initiatives if the children cannot access it (Perrenoud 1998). Esther reflected on some written feedback she had received from her teacher in her literacy exercise book. At one point I asked her what the feedback meant and she commented that this feedback had burdened her with stress because she could not actually read it. Somewhere else, the teacher described her essay as an 'epic', but Esther did not know what the word epic meant. The following interview extract illuminates the perceived inaccessibility of the written feedback she received:

EH: Do ticks mean- what do they mean on this page?

Esther: I don't actually know. She just puts a tick, so I actually don't know what it means. I think it just means "Well done," but I think they should write a comment, because tick, to me, doesn't actually mean anything. It's just a line in your book.

EH: Right, so you don't know what that means. Okay. Is this the last one? No. Okay, here she's put "Excellent notes, Esther." What did you think about when you got that? Esther: I thought l'd written good description, maybe, but I think she should write what's excellent about it, because putting "Excellent notes" won't actually tell me to 
keep writing what l've done. Because if I know that l've done good adverbs, then I know that I need to keep doing that and keep that up, but just putting "Excellent notes" doesn't actually help.

EH: ... Then next page she's put a smiley face. "Excellent detail and description included."

Esther: Mm. I think this bit's good, because it actually tells, "Detail and description." Then I know I'm good at that, and I need to keep that up. But just putting "Excellent" doesn't actually help.

Similarly, Esther did not find it useful when the teacher simply put 'sp' against a spelling mistake in her writing, as she did not assume it was her own role to look up the correct way of spelling the word. In like vein, Laila sounded quite angry when she commented that praise was sometimes of no use for her future self- improvement:

[Teacher] says 'Great, great, great'. She doesn't actually say what is great about it. She needs to actually tell us the point so we can improve the rest and what's not so great.

Therefore, although the children wanted the chance to work things out for themselves, in some situations they ignored the chance to take the initiative and actually welcomed the teacher doing most of the work for them through her feedback. Whilst this runs counter to the arguments favouring teachers' provocative rather than convergent feedback, it may well be that on some occasions it is most effective when teachers spell a message out directly. Since they are in school five days out of seven, so long as the children receive plenty of provocative feedback at some point during the week, some direct telling may be most helpful. Esther did, however, highlight as one of the most effective pieces of feedback she had been given, the occasion when the teacher introduced her to an online thesaurus when she had asked how to spell a word. Esther had used this thesaurus repeatedly since then, both at school and at home. The long-lasting impact of this piece of feedback accords with Hattie and Timperley's (2007) finding that feedback focused on learning processes tends to have the most impact in the long term. Clearly, a balance must be struck between the teacher giving enough support but not undermining the child's sense of autonomy. The balance might be different for different topics or occasions and for different children.

The children felt their learning was supported by feedback reminder cues

Sometimes, the children explained, a little cue or prompt through feedback was a sufficient trigger for subsequent learning which '... all came flooding back' [Farhana]. Most of the children [Aaron, Esther, Farhana, Josh, Maddie, Mia] were very aware of how much children have to remember, recognising that '... you can't remember everything' [Maddie] and therefore the teacher's feedback kept reminding you. Josh and Esther agreed with Maddie that all Year 5 children needed reminding about punctuation. Reminding, of course, is especially necessary in relation to a curriculum such as the one in England, whereby learning objectives are prescribed in some detail. Examiners were hinted at in the teacher's classroom feedback as the people who would be checking up on children's punctuation.

Esther found it useful to listen to the feedback her teacher gave others when the teacher was observed asking around class for examples of individual children's alliterated sentences. Esther was acutely aware of praise given to other children, which she coveted. She told me,

Because Mia, I think Mia, or one of them, put [a simile] in and got praise. I thought, 'If I put one in, it might make my writing better and I might get a bit [of praise]'. 
This contrasted to Josh who was busy writing instead of listening to the teacher's feedback, in case she asked him what he had written.

The children noticed that negative and positive feedback provoked emotions which could interfere with or support learning

Josh craved praise feedback for his own sentences, without relating it to praise given to others. Praise showed him he was better than others; this encouraged him to continue to try to out-perform his peers. Josh's account recalls Henderlong and Lepper's (2002) claim that praise and rewards direct attention away from learning, offer little helpful information for future learning and also undermine children's self-regulation. However, some of the children [Esther, Laila, Jed and Mia] said they felt that praise encouraged them to keep learning. Notably, Mia told me how she had received praise for acting on written feedback given previously, and this had encouraged her always to check her feedback and take action. However, a 'performance orientation' rather than a 'learning orientation' seemed evident among these children (Torrance and Pryor 1998 based on Dweck 1986), for example, when Dave claimed that he only knew his work was right because the teacher said so. And Esther observed that, 'If [teacher] knows I can do it, then I know I can do it'. A similar lack of independence was indicated by Laila who described slowing down when the teacher told her she had done something wrong and Dave agreed that this made one lose concentration.

Aaron described how negative feedback to his friend could affect his own learning because he felt more emotionally attached to his friend than to his teacher. He claimed that if the teacher tells off a friend, the other children '... kind of slow down because the're so angry with her about [telling off] the other person'. Aaron seemed to have a heightened awareness of emotional states and their effect on learning.

Hattie and Timperley (2007) have suggested that when the 'self' is implicated in the teacher's feedback, learning may be impeded by the learner's emotional reaction to such feedback, whether negative or positive. The profile children described a range of negative emotions associated with the teacher's feedback, which might be linked to disrupted learning: in addition to anger, they mentioned frustration, fear, embarrassment, hostility and confusion. Maddie summed up how her mood might affect her learning by saying if she was 'really in the zone', she might take on board more difficult words suggested by the teacher, but this would not be the case if she was not in the mood. While Esther thought that being shouted at could help her to remember her spellings, Farhana at the opposite extreme described great embarrassment and confusion when she did not really understand the teacher's feedback, which led her to avoid giving the teacher definitive answers in case she was wrong. Laila also became fearful of receiving the teacher's feedback, in case she was wrong. Dave commented, 'When you get to know someone, you can just look at their face and know what they're thinking'. He and Laila found the teacher's physical appearance scary when they had done something wrong, and we can assume this might have obstructed learning:

Laila: Well, it's sometimes scary when she says [that you're wrong]... it's kind of, like, her eyes. When she's looking at your book, like I saw in a film, when she looks up at you, her eyes just look up at you...

Dave: And when she looks down at you it's even worse, because her glasses are kind of magnified.

All the children expressed anger and upset that the teacher did not give them more individualised feedback. Each group of children thought the other groups got more feedback than they did. Farhana explained how useful it was when the teacher did give you individualised feedback: 'She's actually talking to you, telling you what you need to improve on'. Among the lower achievers, Dave and Laila noted with indignation that the teacher's feedback was inconsistent: feedback to Dave was that he must join his writing up, while Laila 
did not have to; Dave was corrected for writing outside the box on the sheet of paper while Laila was allowed to. Dave's interpretation of these disparities was that boys are usually messier than girls: but Laila objected to this explanation. These perceptions did, however, reveal the children's awareness of the potential for bias in feedback, including gender bias.

As well as the negative emotions associated with feedback that potentially hindered learning, the children mentioned the positive impact of amusing feedback. Aaron told me categorically that jokey feedback encouraged him to learn, and fortunately Mrs. K. used humour in her teaching: apparently, 'She has to go in the cupboard and stuff just to laugh!' [Laila]. Whilst sometimes Mrs K. made a joke as feedback at the expense of the children, the profile children were not offended. For example, Esther did not mind when Mrs K. yawned in jest when she saw how much Esther had written and Esther noted, smiling, that Mrs. K. was trying to encourage her to write more succinctly.

\section{Assessment for Learning, teacher feedback and children's sense of autonomy: discussion}

This research has added some important detail to understandings about how teacher feedback relates to children's learning. Key details are revealed through the children's claim that learning was frustrated by overly directive feedback and their observation that learning benefited when the teacher's feedback gave substantial but not burdensome detail. Other noteworthy details are provided through the children's insight that their learning was supported by feedback reminder cues because of the amount they needed to remember, and of particular importance, their noticing that negative and positive feedback provoked emotions which could interfere with or support learning.

This research illuminates Hattie and Timperley's (2007) claim that some children are better at monitoring their own learning than others. Some children were more willing to invest effort into seeking and dealing with feedback, although this might be hampered by classroom conditions such as having to wait a very long time to get the teacher's attention. Some children were more confident that they were doing well which tended to spur them on to respond to feedback. However, the differences were not just among the nine children but also among each child's different states. On some occasions, one child might be hungry for self-regulating opportunities, at others they craved directives, and this was affected by their shifting emotions which in turn were partly the result of the feedback they received.

The children in this Year 5 class were evidently very capable of contributing to our understanding of how feedback works for them. All the children suggested that they were attuned to the teacher's feedback of approval or disapproval, and seemed to be motivated by a performance orientation in their dependence on the teacher's approval feedback. For example, they said they sometimes felt helpless on their own, avoiding risk taking and finding it hard to work through set-backs. Negative, learning-inhibiting emotional states were sometimes the consequence of the withdrawal of teacher approval although, at least temporarily, positive emotions and increased engagement could result from receiving the teacher's approval. The teacher's feedback was frequently given within a convergent assessment framework where convergent, rather than divergent, answers were sought. Within this framework, they said they found reminders useful, and simple prompts, cues or instructions. However, they indicated that they became frustrated or even very frustrated when the teacher either tried to tell them the answers when they could work them out themselves, or gave them repeated reminders that they did not need. They were perhaps sensing the teacher's anxiety about impending assessments in the following year and the very natural response of teachers to try to control more when they feel anxiety. It would not be surprising if the teacher's tendency to control through feedback limited the children's sense of autonomy (see Ryan and Deci 2000). 
The children described some teacher feedback that seemed to promote autonomy directly, such as the teacher's provocative questions, demonstration of a long-term strategy and explanations for why their work was good or poor. The ensuing autonomy was defined in terms mainly of independence and to some extent as the taking of initiative. Criticality was not obvious in the children's responses to the teacher's feedback. However, through participating in this research, some of the profile children did seem to take a more critical stance, in the sense of questioning the status quo and wondering how things could be different and better for their learning. As the research proceeded, the children became more open and more discerning about how the teacher's feedback affected their learning. Such a conversation is likely to have supported their learning processes and at the same time enhanced their critical autonomy. Conversations about learning and the learning environment, including the teacher's feedback, are key ingredients for ensuring that children's learning autonomy flourishes. In this area the teacher does not have all the answers, because the success of her teaching depends on the reactions of her children. Thus both parties must reflect, converse and make changes.

Allal and Mottier Lupez $(2005,244)$ have described AfL itself as a privileged occasion for conscious reflection, in which both teacher and learner adapt to each other. This reciprocal process could encourage children both to take initiatives and to engage in critical autonomy. The actions and views of children and teacher are by necessity equally valuable, and either can lead to short term pedagogical changes or long term changes in social perspectives. James, Pedder and MacBeath $(2005,216)$ stressed the initiative-taking of children in the autonomy towards which AfL is driven:

Students as well as teachers have an explicit role in instigating classroom teaching and learning. Students are not merely the objects of their teacher's behaviour, they are animators or co-constructors of their own effective teaching and learning processes.

Pryor and Crossourd $(2008,8)$ emphasised the critical aspect of autonomy through the teacher's focus on the meta-social. They described AfL as having the following:

An explicit aim of raising students' critical awareness both of the discourses of the educational setting, and also of the wider social construction of these discourses... The pedagogic texts and the teaching context therefore become the object of critique, rather than functioning to 'deliver' knowledge.

In a survey of 83 teachers and head teachers reported by Hargreaves (2005), one subsection of respondents defined AfL as teachers learning about children's learning. For example, respondents cited Looking at how children pick up ideas and how we can support them in this process and Seeing where the child is: how does the learner learn? How do they perceive learning? How are they motivated? This definition was related to another whereby AfL meant children taking some control of their own learning and assessment, for example, Children talking and reflecting on their own learning in order to develop and grow and Children having some element of control over how/what/why they are learning. In these models of AfL, the subject for assessment is the teacher's feedback and the children's learning; the information derived is how these two impact on each other; and the next steps can then be planned through a dialogue between teacher and children about what is helpful to learning and what is less helpful. In assessment terms, the data used in this model are the children's and teacher's insights into the teacher's feedback and the children's learning.

The research I describe in this paper provides a starting point for exploring AfL in the sense of the teacher learning about her learners; and of learners initiating and critiquing her feedback and their own learning in dialogue with her. However, it is a starting point rather than an example of AfL in practice because in the case of this research the teacher did not 
initiate the research process and she learnt about the children's comments only through reading anonymous statements. Whether she would or could have led such a process herself is questionable. Indeed, the children may not have felt able to talk freely to their teacher and the teacher may have been uncomfortable about improving her teaching on the basis of children's comments (see also Ferguson, Hanreddy and Draxton 2011). This project has highlighted how honest conversation may take time to develop. In a climate of summative judgements of teachers and children alike, it is only a very learning-oriented teacher who dares to open up the conversation with her class about how she and the class can enhance learning, based on both the children's observations and her own. In this case, it is likely that the learning they discussed would not be limited to attaining prescribed statements of achievement. They might want to discuss the diverse social and interactional situations in which learning occurs and their range of feelings within those which affect their responses to the teacher's feedback: this is because their unscripted participation in the dialogue is likely to benefit them directly as they learn first hand about being autonomous human individuals.

\section{References}

Allal, L. \& L. Mottier Lupez (2005) Formative assessment of learning: a review of publications in French, in OECD, Formative assessment: improving learning in secondary classrooms (OECD, Paris), 241-264.

Asevedo, R., \& R.M. Bernard (1995) A meta-analysis of the effects of feedback in computerbased instruction, Journal of Educational Computing Research, 13, 111-127.

Bassey, M. (2001) A solution to the problem of generalisation in educational research: fuzzy prediction, Oxford Review of Education, 27, 5-22.

Black, P. \& D. William (1998) Assessment and classroom learning, Assessment in Education, 5, 7-74.

Brookhart, S. (2001) Successful students' formative and summative uses of assessment information, Assessment in Education, 8, 153-169.

Butler, D. \& P. Winnie (1995) Feedback and self-regulated learning, Review of Educational Research, 65, 245-81.

Cohen, L., L. Manion \& K. Morrison (2007) Research methods in education (Oxford, Routledge).

Department for Children, Schools and Families (2008) The assessment for learning strategy (London, DFSF).

Dennison, B. \& Kirk, R. (1990) Do, Review, Learn, Apply (Oxford, Blackwell.)

Dweck, C. (1986) Motivational processes affecting learning, American Psychologist, 41, 1040-1058.

Ecclestone, K. (2002) Learning autonomy in post-16 education (London, RoutledgeFalmer). Fergurson, D., A. Hanreddy \& S. Draxton (2011) Giving students voice as a strategy for improving teacher practice, London Review of Education, 9, 55-70.

Fisher, H. (2011) Inside the primary classroom: examples of dissatisfaction behind a veil of compliance, British Journal of Educational Studies, 59, 2, 121-141.

Hargreaves, E., B. McCallum \& C. Gipps (2000) Teacher feedback strategies in primary classrooms: new evidence, in: S. Askew (Ed) Feedback for learning (London, RoutledgeFalmer), 21-31.

Hargreaves, E. (2005) Assessment for learning? Thinking outside the black box, Cambridge Journal of Education, 35, 213-224.

Hargreaves, E. (2012) Teachers' classroom feedback: still trying to get it right, Pedagogies, 7, 1, 1-15.

Hattie, J. \& H. Timperley (2007) The power of feedback, Review of Educational Research, 77, 81-122.

Henderlong, J. \& M. Lepper (2002) The effects of praise on children's intrinsic motivation: a review and synthesis, Psychological Bulletin, 128, 774-795. 
Kluger, A. \& A. DeNisi (1996) The effects of feedback interventions on performance: a historical review, a meta-analysis, and a preliminary feedback intervention theory, Psychological Bulletin, 119, 254-284.

Kulhavy, R.W., M.T. White., B.W. Topp, A.L. Chan \& J. Adams (1985) Feedback complexity and corrective efficiency, Contemporary Educational Psychology, 10, 285-291.

Marshall, B. \& M.J. Drummond (2006) How teachers engage with AfL: lessons from the classroom, Research Papers in Education, 21, 133-149.

Mason, B.J. \& R. Bruning (2001) Providing feedback in computer-based instruction: what the research tells us, Center for Instructional Innovation, University of Nebraska-Lincoln, retrieved June 1, 2006, from http://dwb.unl.edu/Edit/MB/MasonBruning.html

Miles, M. \& A. Huberman (1994) Qualitative data analysis. 2nd Edition (Thousand Oaks CA, Sage).

Mory, E.H. (2004) Feedback research review, in D. Jonassen (Eds) Handbook of research on educational communications and technology (Mahwah, NJ, Lawrence Erlbaum), 745-783. Murnane, R.J. \& F. Levy (1996) Teaching the new basic skills. Principles for educating children to thrive in a changing economy (New York, Free Press).

Narciss, S. \& K. Huth (2004) How to design informative tutoring feedback for multimedia learning, in: H.M. Niegermann, D. Leutner \& R. Brunken (Ed) Instructional design for multimedia learning (Munster, NY, Waxmann), 181-195.

Pedder, D., M. James \& J. MacBeath (2005) How teachers value and practise professional learning, Research Papers in Education, 20, 209-243.

Perrenoud, P. (1998) From formative evaluation to a controlled regulation of learning. Towards a wider conceptual field, Assessment in Education, 5, 85-102.

Pryor, J. \& B. Crossouard (2008) A socio-cultural theorisation of formative assessment, Oxford Review of Education, 34, 1-20.

Pryor, J. \& H. Torrance (1998) Formative assessment in the classroom: where psychological theory meets social practice, Social Psychology of Education, 2, 151-176.

Ryan, R. \& E. Deci (2000) Self-determination theory and the facilitation of intrinsic motivation, social development and well-being, American Psychologist, 55, 68-71.

Shute, V. (2008) Focus on formative feedback, Review of Educational Research, 78, 153189.

Torrance, H. \& J. Pryor (1998) Investigating formative assessment (Buckingham, Oxford University Press).

Tunstall, P. \& C. Gipps (1996a) Teacher feedback to young children in formative assessment: a typology, British Educational Research Journal, 22, 389-404.

Tunstall, P. \& C. Gipps (1996b) How does your teacher help you make your work better? Children's understanding of formative assessment, Curriculum Journal, 7, 185-203.

Watkins, C. (2001) Learning about learning enhances performance (London, Institute of Education School Improvement Network).

Weeden, P., Winter, J. \& P. Broadfoot (2002) Assessment: what's in it for schools? (London, RoutledgeFalmer).

Yandell, J. (2007) Investigating literacy practices within the secondary English classroom, or where is the text in this class? Cambridge Journal of Education, 37, 2, 249-262. 